\title{
Cognitive Concept of the Analysis of Hype Processes in the Digital Economy
}

\author{
Vladimir F. Minakov 1[ORCID 0000-0001-6380-9091], \\ Sergei A. Dyatlov 1[ORCID 0000-0001-7724-6373], \\ Oleg S. Lobanov 1[ORCID 0000-0002-0878-2380], \\ Tamara A. Selishcheva 1*[ORCID 0000-0001-6787-9150]
}

\author{
${ }^{l}$ St. Petersburg State University of Economics, Saint Petersburg, Russia \\ selishcheva@list.ru
}

\begin{abstract}
This article is devoted to study the digital transformation features of socio-economic processes in the context of COVID-19 pandemic. Regularities of digital transformation and reorientation of business processes to vector of high technologies, automatic and robotic systems, neural networks, artificial intelligence, Internet of things, cyberphysical systems with cognitive functions, leading to an increase in synergetic effects and a decrease in entropy are revealed.Analysis of conditions and factors of the emergence and course of hype processes in a number of industries and spheres of economy is given: a hype change in demand in cryptocurrency markets; high growth of NASDAQ high-tech stock index; dynamics of abnormal changes in the share price of GameStop. It is determined that arising processes caused by influence of large flows of information develop in time according to model of hype cycle curve. Authors' interdisciplinary approach to model development of cognitive-network hype processes that reduce entropy in management of socio-economic systems subject to replication and mass use, including in automatic mode in WEB services, has been substantiated. A cognitive production function is proposed that takes into account decomposition and accounting of cognitive production factors, intellectual property objects and creative abilities of personnel, whose activities generate new knowledge and lead to emergence of new cognitive functions. It is concluded that the most important effect of digital cognitive-network transformation is a decrease in entropy and exponential economic growth based on dominance of increasing returns over decreasing productivity with an extensive increase in volume of traditional factors (labor and capital). A significant effect of cognitive digital transformation in context of digital convergence of cognitive and traditional production factors is to obtain synergistic effects and counteract the growth of entropy caused by explosive growth of hype processes under the influence of large volumes of information hypes.
\end{abstract}

Keywords: digital transformation, hype, convergence, entropy, neural network economics

\section{INTRODUCTION}

Recently, in many areas and spheres of economic and socio-political life, hype cycle has begun to gain momentum. The hype cycle framework is widely used to analyze dynamics of innovation processes, high-tech products and IT solutions. In our opinion, it is advisable to expand the scope of this framework to financial, economic and socio-political processes.

Digitalization of economic processes and systems during the coronavirus period has led to formation of a stable, adequate remote activities, as well as an adequate digital infrastructure. This transformation has become a reality of digital transformation of socio-economic systems [1].

It is important to note that remote interaction has significantly expanded not only along horizontal process management and execution of decisions, but also along vertical management, up to state and interstate interaction. As a result, there was a transformation of dominant methods of interaction not only in the search and analysis of alternatives to goods and services on the market, but, most importantly, along the entire chain of added value and 
final consumer value, as well as generating cash flows, financial transactions. In Russia, share of noncash payments in retail trade increased (up to $70.3 \%$ by the end of 2020). The dominance of non-cash payments in the field of financial settlements of legal entities has become stable and irreversible. This has significantly reduced the cost of financial transactions in the national economy. The transformation of value chains is an irreversible transformational process of the modern economy, in which digital resources, for example, Internet aggregator platforms, are becoming more in demand and displace (replace) a large cluster of economic entities with traditional business models [2].

Thus, redistribution of preferences in the assets formation of economic entities is being scaled up [3]. Rush demand is observed in the cryptocurrency markets. As a result, the most popular of them surpassed the $\$ 61000$ (per bitcoin) cost threshold Figure 1 (according to quotes from investfunds.ru). This growth compared to the beginning of 2020 was over $750 \%$. It is important to note that the basis for transformation of such preferences is, firstly, an appetite for risk, and, accordingly, an increase in asset returns, and, secondly, a high level of people's trust in digital technologies (bitcoin has no other types of collateral).

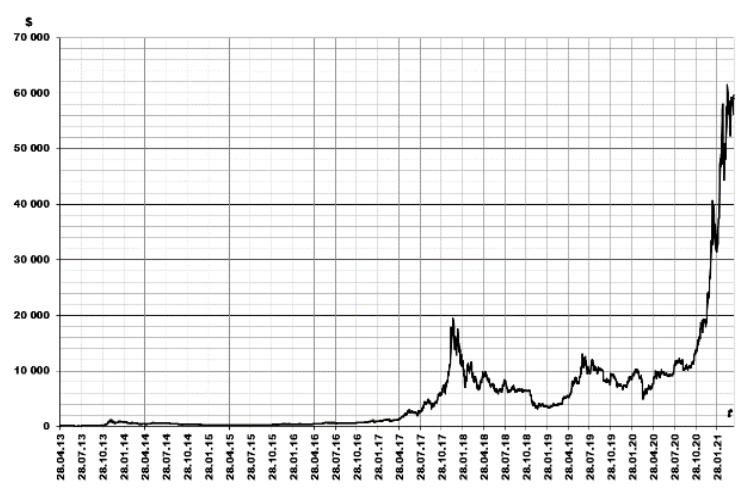

Figure 1. Dynamics of Bitcoin exchange rate Source: Compiled by the authors

Digital transformation in the minds of service users is associated with an increase in interest, trust in digital resources, and the efficiency of their use. The growth in the security of IT and telecommunications plays a role. Practice confirms this growth of confidence in information tools for remote work and interaction between employees of enterprises and stakeholders, virtual provision of goods and services, organization of transport services (and logistics), delivery of goods to end consumers.

Reorientation of business processes towards the use of high technologies, automatic and robotic systems, smart algorithms, artificial intelligence, Internet of things, as well as technologies of the 4th industrial revolution becomes a regularity. In general, high-tech companies have significantly strengthened their positions. The dynamics of stock index growth of companies in high-tech industries and, especially, in the field of digital technologies, NASDAQ is shown in Figure 2 (according to quotes from investfunds.ru).

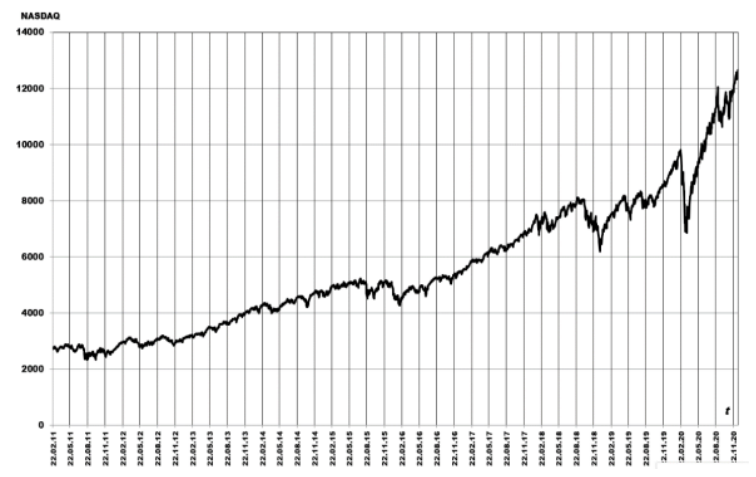

Figure 2. Dynamics of the NASDAQ index Source: Compiled by the authors

Comparative dynamics of the Dow Jones and S\&P 500 indices based on investfunds.ru quotes is presented in Figure 3 and Figure 4.

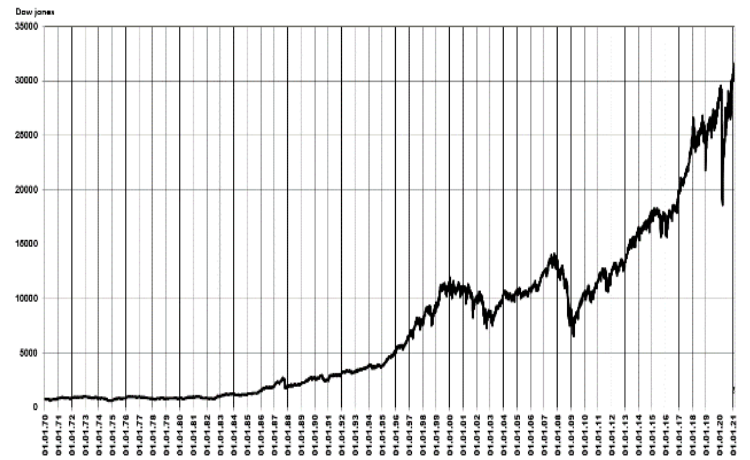

Figure 3. Dynamics of the Dow Jones index Source: Compiled by the authors

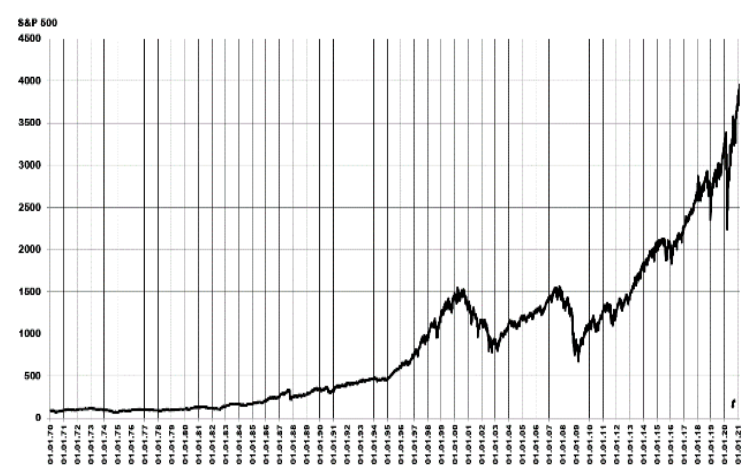

Figure 4. Dynamics of the S\&P 500 index Source: Compiled by the authors 
The comparison shows that economic processes require and widely use high-tech methods of organizing the production of goods and services, and especially digital methods and means of production [4]. Interest has grown in implementation of cyberphysical systems (CPS) with cognitive functions. Reproduction of thought processes by methods and means of knowledge production based on digital technologies solves the problems of managing production processes in real time [5].

Such methods open up great prospects in the processes of substantiating and making effective management decisions at both operational and tactical and strategic levels. In this regard, development of intelligent methods, algorithms and software controls is intensified. They are being actively tested in control systems for unmanned vehicles, production equipment, workshops, smart factories, workshops, smart cities. In this way, companies prefer to solve problems of training personnel with modern competencies, including new functions of networked human capital. It is necessary to take into account the effects that arise as a result of digital convergence in management systems at the regional, national and international levels $[6,7]$.

In this regard, an urgent task is to study new patterns of digital transformation in economics and management, leading to an increase in synergetic effects and a decrease in entropy, which is the purpose of this work.

\section{MATERIALS AND METHODS}

Economic theory has long established the importance of information influence on markets, their equilibrium states, and, conversely, the disturbances formation, and, accordingly, a deviation from equilibrium states and the effectiveness of the invisible hand of the market. So, Yu. Fama [8] put forward the efficient market hypothesis, which affirms the absolute influence and information accounting in the prices of stock market assets. Together with L. Hansen [9, 10] and R. Schiller [11] for the study of dynamic processes of price changes in stock markets were awarded the International Prize in Economics A. Nobel. The authors have established the possibility and manifestation of not only rational, but also irrational decisions in the specified market.

A wider range of markets, their dynamics under the influence of information resulting in the need to change of economic theory paradigm under the influence of information and innovation was substantiated by J. Stiglitz [12].
Today, there is a need to establish the influence, along with traditional factors, information and cognitive factors on the deep transformation of all elements in the economic system (network business, network management, network educational services, network human capital, etc.). It is required to identify and systematize innovative neuro-cognitive resources and cognitive functions, to determine their role and functions in hybrid neuro-network economic systems.

Transition to a new technological paradigm is based on the widespread use of digital ecosystems, convergent neural network technologies and neural network artificial intelligence. Cognitive methods and digital technologies for their implementation are being developed through usage of big data and tools for analytics, artificial intelligence, neural networks, modeling (the scope of application of digital twins is being actively expanded) and many others.

Transformation is inherent not only in digitalization of information itself, but also in goals and objectives of users (and agents of economic processes) who give preference to digital information resources. It is also important that efficiency of using digital information flows is significantly higher than traditional ones and gives competitive advantages to companies [6]. As a result, digital transformation processes in workflow and information dissemination systems can be classified as natural and irreversible.

Particularly noteworthy is the role of such information, which expresses the knowledge necessary not only for implementation of technological processes, but also for making management decisions. Obviously, in management of socio-economic processes, a big problem is uncertainty, especially in connection with changes taking place under influence of the pandemic which consequences are still unknown [13]. Due to the unprecedentedness and lack of experience in finding a way out of this situation, there are no experts in this situation, as well as knowledge necessary for informed decision-making. Priorities for the formation of a new business cycle remain unclear [14, 15].

To gain the kind of knowledge that reduces uncertainty, decision-makers turn to information that reflects (and expresses) both experience and theories that provide knowledge. A new problem arises here. The experience of previous periods of time may turn out to be negative, since it was obtained in other conditions, significantly different from the coronacrisis realities. The new conditions are characterized by irreversibility, that is, irreversibility to previous indicators and even patterns of economic processes. 
In addition, the influence of digital information flows on the consciousness of the masses of people has significantly increased (the consciousness of people has also been transformed in terms of the redistribution of value priorities). As a result, there are processes that contradict the results of fundamental analysis, caused by changes in the behavior of actors in socio-economic systems, up to anomalies of an irrational nature. It is important to note that their scale, due to high speed of information spreading in a wide range of economic entities, radically changes the indicators of market conditions. Moreover, rush processes arise due to the influence of information flows (including fake information). For this reason, a large share of economic processes develops over time according to the typical curve of a hype cycle [16] (Figure 5).

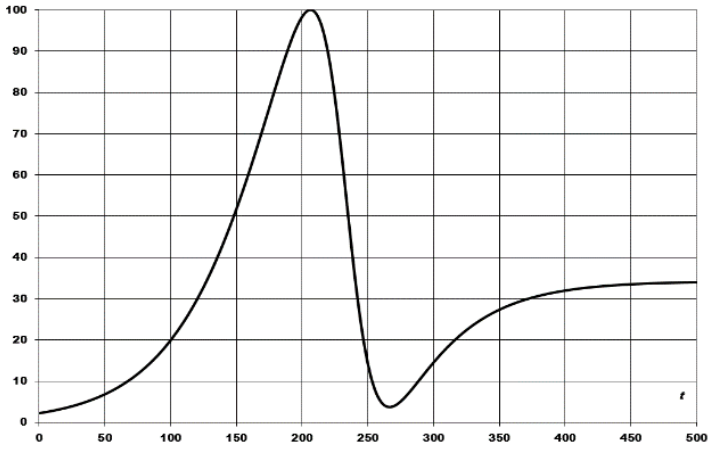

Figure 5. Hype Cycle ( $V, \%)$

Source: Compiled by the authors

Indeed, dynamics of abnormal changes in GameStop stock price over a very short period of time in 2021, shown in Fig. 6 (according to quotes from investfunds.ru), is a reflection of hype anomalies. Uncertainty and, accordingly, chaos of the main players' behavior caused opposite actions: on the one hand, of hedge funds, which sold in short shares with subsequent redemption, and on the other hand, a chaotically formed "group" of supporters of the company's activities, who organized a massive purchase with a network appeal promotions. As a result, not only hedge funds fail to profit from their short positions, but conversely, they lost billions of US dollars on their buybacks at substantially higher prices. As we can see from the graph, on January 4, 2021 , the share price was $\$ 17.25$, and already on January 27 - \$347.51 (an increase in 23 days was $1914.55 \%$ ). In this case, uncertainty was created and rose up with the increase in the number of players, on whose actions the outcome depended. It is also important to note that such an increase in entropy was formed on the basis of digital resources exclusively under the influence of information flows.

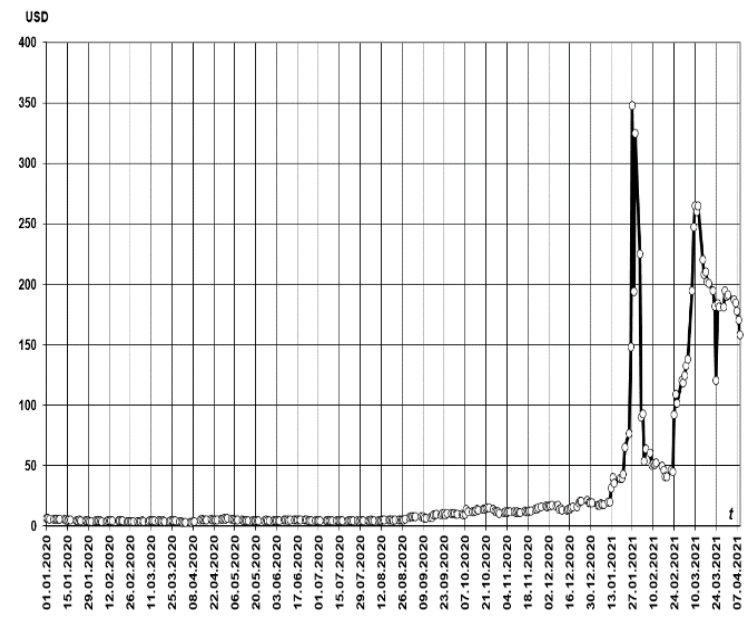

Figure 6. Dynamics of a hype bubble formation on example of GameStop stock price

Source: Compiled by the authors

To prevent such chaotic conditions, and, accordingly, h dynamics, formation of an information flow that counteracts the growth of entropy is required.

Thus, an approach to assessing the state of markets in modern conditions of uncertainty will allow market participants to reasonably form their portfolios of assets, develop their production and seek to improve their efficiency.

Entropy as a metric of uncertainty under such conditions (1):

$$
H=-\sum_{i=1}^{M}\left(p_{i} \cdot \ln \left(p_{i}\right)\right)
$$

where $p$ - the probability of each possible outcomes $(M)$ of the events occurring.

The value of entropy decreases to zero when information about a deterministic outcome appears. This requires knowledge, represented by information in the volume $(z)$, expressed in digital systems by bits unit of measurement (2):

$$
z=-\sum_{i=1}^{M}\left(p_{i} \cdot \log _{2}\left(p_{i}\right)\right)
$$

Thus, development and improvement of production model of economic processes should be based on mathematical description of cognitive processes that reduce entropy in the management of economic systems, and in a formalized model and algorithmic representation - subject to replication and mass use, including in automatic mode (without participation carriers of natural cognitive functions) in WEB-services of global computer networks. 


\section{RESULTS}

Production of the amount of information that expresses knowledge required to reduce the entropy, in accordance with (2), is possible in two ways. The first is acquisition of cognitive activity results in form of patents, know-how, design documentation, technologies $(\Delta z)$ which can be used directly in economic activity. The second is use of cognitive abilities $\left(k_{r}\right)$ of personnel, or intelligent digital systems and technologies, use of which during working hours produces knowledge in volume (3):

$$
z_{k r}=k_{r} \cdot \Delta t
$$

Then the knowledge necessary for the cognitive transformation of economic processes, in the amount (4):

$$
z=\Delta z+z_{k r}=\Delta z+k_{r} \cdot \Delta t
$$

allows, for example, to increase production volumes. Hence the well-known traditional production function (5)

$$
V_{k}=A \cdot K^{\alpha} \cdot L^{\beta} \cdot e^{\gamma \cdot t},
$$

where $A$ - scale of production; $K$ - capital used in production, $L$ - labor resources of production; $\alpha, \beta-$ coefficients of elasticity of production with respect to capital and labor; $\gamma$ - rate of scientific and technological development,

can be modernized by representing scientific and technological development as a function of the amount of knowledge and cognitive resources used (4).

So we introduce a cognitive production function that takes into account the influence of knowledge and cognitive resources used as scientific and technological progress (6):

$$
V_{k}=A \cdot K^{\alpha} \cdot L^{\beta} \cdot e^{\left(z+k_{r} \cdot t\right) / z_{0}},
$$

where $z_{o}$ - the initial value $z(0)$ at the moment of origin $t=0$.

A distinctive feature of such a model representation is decomposition and accounting of cognitive factors of production, firstly, in the form of intellectual property objects, and secondly, in the form of personnel' abilities, whose activities generate (produce) new knowledge and lead to emergence of new cognitive functions.

It is important to note that resulting model makes it possible to establish the substitution property possessed by cognitive technologies. Investments in such technologies, especially when they converge with digital systems, firstly, for formation of direct control actions [4] (for example, in business processes), and secondly, for making decisions in operational, tactical and strategic management, are capable to ensure innovative economic growth.

\section{DISCUSSION}

We should pay attention to the fundamental differences in of influence patterns of knowledge and cognitive resources used in comparison with traditional factors - capital and labor. As is known, labor and capital elasticities have numerical values less than unity. Consequently, the effect of investments in these resources is characterized by law of diminishing marginal productivity. The effect of use of knowledge and cognitive resources is characterized by law of increasing marginal productivity, and their use provides, as can be seen from the model, exponential growth (Figure 7).

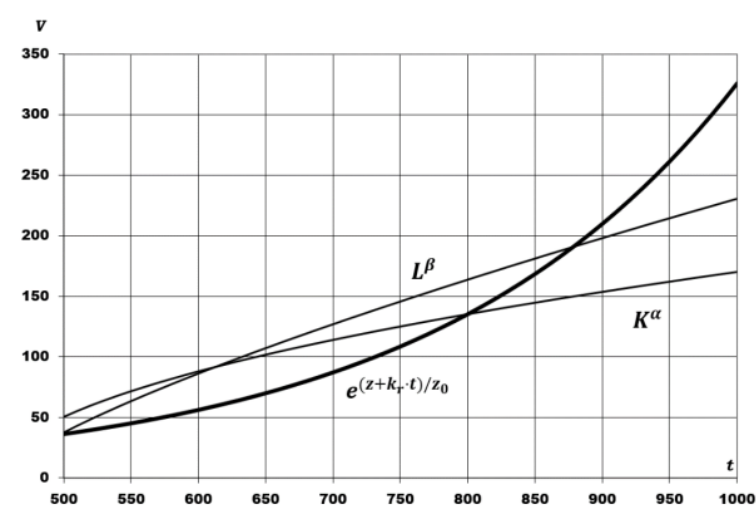

Figure 7. Influence of knowledge and cognitive factors of production in comparison with capital and labor

Source: Compiled by the authors

Simulation results allow us to establish that efficiency of investments in the resources of production processes in comparison with investments in intellectual capital is effective only with a low initial base and within a limited range of such investments. As the law of diminishing productivity manifests itself, the absolute growth in production volumes decreases, which corresponds to decrease in efficiency of production processes. Investments to drive cognitive digital transformation as they grow, on the other hand, lead to exponential economic growth.

This important position is confirmed by fundamental conclusion we formulated earlier that 
synergistic effects arising under the influence of digital innovations during network convergence of information clusters are accompanied by a decrease in entropy [8].

\section{CONCLUSIONS}

The resulting model of cognitive production function makes it possible to evaluate, firstly, the result of production, depending on amount of intellectual capital used and generated knowledge, and secondly, to solve the inverse problem of determining the required increment of knowledge to achieve the target volume of production.

Management of economic systems, taking into account the cognitive factor of production, not only provides an increase in its volume, but also competitive advantages for business entities. It is important to note that cognitive parameters in a production function drastically change its nature. If, with a low initial base, dominant effect in the form of an increase in production volume can be obtained through investments, and, accordingly, an increase in size of capital or labor used, then with a high base ( $\mathrm{K}$ and $\mathrm{L}$ ) and production volumes, increase in volume of production results in manifestation of law of diminishing returns goes down. Usage of cognitive functions, on the contrary, leads to higher rates of production growth at large volumes, when force of law of increasing returns becomes dominant. In Figure 7, which visualizes the nature of cognitive factors influence on production in comparison with capital and labor, the excess zone of manifestation force of the law of increasing returns is formed after intersection of cognitive functions effect over functions of traditional factors influence. It should be noted that labor and capital are finite in terms of production factors volumes, while cognitive factors, when they interact with artificial intelligence systems, have property of scalability and are replicated by a fairly large circle of interested users, including a huge number of global networks users.

Consequently, the digital transformation paradigm in economy is naturally based on an increase in the importance and depth of penetration of cognitive-network digital systems and technologies, methods and models of knowledge production in such systems and their practical use in transforming economic systems. The most important effect of cognitive-network digital transformation is a decrease in entropy and exponential economic growth based on dominance of increasing returns over decreasing productivity with an extensive increase in volume of traditional factors (labor and capital). In cases where cognitive technologies form cooperatives, aggregators and system integrators, there is a synergistic effect of exceeding results of activities over the sum of individual stakeholders' results.

A significant effect of cognitive digital transformation is counteraction of increasing entropy under influence of information hypes, when the volume of information grows like an avalanche, ranging from "fakes" to viral advertising, which complicates the adoption of effective decisions by business entities. Moreover, information rush flows are perceived by market agents, causing anomalies in asset prices, inflation of bubbles, and subsequently their inevitable burst. And only cognitive technologies allow in such cases to substantiate the decisions made, including those that provide a way out of abnormal, irrational and even crisis processes and states.

\section{AUTHORS' CONTRIBUTIONS}

The authors made an equal contribution to the study: collection and analysis of material; definition of goals and objectives, research methods; formulation and scientific substantiation of conclusions, registration of key research results in the form of an article.

\section{ACKNOWLEDGMENTS}

The reported study was funded by RFBR and EISR, project number 21-01131179.

\section{REFERENCES}

[1] V.V. Glinsky, L.K. Serga, S.V. Tsurikov, V.S. Plotnikov, "Analysis of the digital transformation influence on the economic growth of the region", Economic and Social Development: 54th ISC on Economic and Social Development, 2020, pp. 260-269.

[2] V.M. Abramov, E.P. Istomin, S.I. Bidenko, V.V. Novikov, E.A. Yaily, "Big data and internet of things technologies within geo-information support for black carbon control in arctic", In Proceedings of 19th International multidisciplinary scientific geoconference, 2019, pp. 793-800. DOI: 10.5593/sgem2019/2.1/S08.103

[3] L.K. Bobrov, A.A. Kiselnikov, O.Yu. Ryzhkov, V.N. Borisov, "Actuarial methodology of assessment of enterprise risks", Economic and 
Social Development, 54th ISC on Economic and Social Development, 2020, pp. 173-182.

[4] A.A. Akaev, D.N. Desyatko, A.A. Petryakov, A.I. Sarygulov, "Regional development and the education system in the context of digital transformation", Economy of Region, 2020, vol. 16(4), pp. 1031-1045. (In Russ.). DOI: 10.17059/ekon.reg.2020-4-2

[5] S.A. Dyatlov, O.S. Lobanov, Z. Weidi, "The management of regional information space in the conditions of digital economy", Economy of Region, 2018, vol. 14(4), pp. 1194-1206. (In Russ.). DOI: 10.17059/2018-4-11

[6] O.S. Lobanov, S.A. Dyatlov, "The effects of convergence of regional systems in the digital economy", In Proceedings of 3rd ISPC, DEFIN, 2020, p. 3390814. DOI: $10.1145 / 3388984.3390814$

[7] T.A. Selischeva, S.A. Dyatlov, O.S. Lobanov, "Information space convergence as a new stage of e-governance development in Eurasian economic space", In Proceedings of IC "Electronic Governance and Open Society: Challenges in Eurasia" (EGOSE`17), 2017, pp. 99-106. DOI: 10.1145/3129757.3129775

[8] B.G. Malkiel, E.F. Fama, "Efficient capital markets: A review of theory and empirical work", The Journal of Finance, 1970, vol. 25(2), pp. 383-417.

[9] L.P. Hansen, "Generalized Methods of Moments: A Time Series Perspective", International Encyclopedia of the Social and Behavior Sciences, 2000, vol. 17, p. 500.
[10]L.P. Hansen, "Large Sample Properties of Generalized Methods of Moments Estimators", Econometrica: Journal of the Econometric Society, 1982, vol. 50, pp. 1029-1054. DOI: $10.2307 / 1912775$

[11]R.J. Shiller, "Market volatility and investor behavior", The American Economic Review, 1990, vol. 80(2), pp. 58-62.

[12] J. Stiglitz, "Information and paradigm change in economic theory", Ekovest, 2003, vol. 3, pp. 336-421.

[13] V. Borisov, Y. Fedulov, M. Dli, A. Zaenchkovsky, "Method for identification, stability analysis and the dynamics monitoring of sociotechnical clusters", Journal of Physics: Conference Series, VI ISPC "Virtual Simulation, Prototyping and Industrial Design 2019”, 2020, p. 012018.

[14] V. Glinskiy, L. Serga, M. Khvan, K. Zaykov, “A spatio-dynamic modelling of environmental safety of the Russian Federation regions", Procedia Manufacturing, 2017, vol. 8, pp. 315322. DOI: $10.1016 /$ j.promfg.2017.02.040

[15] V. Glinskiy, L. Serga, M. Khvan, K. Zaykov, "Fuzzy neural networks in the assessment of environmental safety", Procedia CIRP, 2016, pp. 615-619. DOI: 10.1016/j.procir.2016.01.143

[16] V.F. Minakov, O.S. Lobanov, S.A. Dyatlov, "Three-Dimensional Trends Superposition in Digital Innovation Life Cycle Model", International Journal of Technology, 2020, vol. 11(6), pp. 1201-1212. DOI: 10.14716/ijtech.v11i6.4444 